\title{
Experiential response and intention to purchase in the co-creative consumption of music: the Nine Inch Nails experiment
}

\begin{abstract}
Customers allowed to co-create products are more willing to purchase them eventually, because of their utilitarian but also their hedonic and experiential value. Experiential responses seem especially relevant in the co-creative consumption of cultural and intangible goods, such as music. To examine how such intangible aspects of co-creation can influence a consumer's intention to purchase, we let two groups of participants rate their experience consuming music in either a traditional or co-creative way, in an experimental situation inspired by the work of American rock band Nine Inch Nails. Participants in the traditional group had to passively watch a series of music video; participants in the co-creative group were tasked to produce a video montage using the same material. In the traditional group, purchase intention was predicted by music quality, mediated by willingness to re-experience; in the co-creative group however, purchase intention was only predicted by the consumers' experiential response, with no mediation of either music quality or willingness to re-experience. Additionally, the overall experiential response to music was lower in the co-creative group than in the traditional group, leading to lower intention to purchase. These results confirm that co-created value for intangible goods is predicted at least as much by the consumers' experiential response as by their evaluation of product quality. It also suggests that there is nothing systematically positive in having consumers participate in the co-production of intangible goods, and that research is needed to identify the factors predicting the perceived quality of a co-creative experience.
\end{abstract}

Keywords: co-creation, hedonic, experiential, music

\section{Introduction}

Co-creation (Prahalad and Ramaswany, 2004) is the business strategy to emphasize active relationships between a firm and its customers. Epitomized by a series of innovations in the manufacturing industry, in which customers were allowed to either select what products would be marketed (Fuchs et al., 2010) or even design the products themselves (Franke and Piller, 2004), cocreation has invaded other areas such as retail or marketing (Durgee, 2003). According to service-dominant logic, co-creation creates additional utilitarian value for customers because customized products more closely reflect their individual needs (Franke and Piller, 2004). But a series of recent studies (Schreier, 2006; Fuchs et al., 2010; Franke and Kaiser, 2010) have brought increasing light to other non-utilitarian benefits of co-creative con- sumption: even when controling for their utilitarian benefits and the effort invested in their creation, co-created products generate greater willingess-to-pay (Franke and Kaiser, 2010), explained by psychological reactions such as a customer's feeling of accomplishment (Franke and Kaiser, 2010), empowerment (Fuchs et al., 2010), pride of authorship (Schreier, 2006), reward and fun (Füller, 2010). In other words, the co-creative process not only meets the customers' functional needs, but also their hedonic or experiential needs. The "process" is valued at least as much as the "product" (Schreier, 2006).

While co-creative consumption is best illustrated with mass-customized manufactured goods, it is also becoming increasingly frequent with cultural and intangible goods. Opportunities for co-creative consumption of media in particular has increased exponentially in recent years, 
driven by the development of social media. In 2010 already, $37 \%$ of internet users were found to contribute to the creation of news, commented about it, or disseminated it via postings on social media sites like Facebook or Twitter (Purcell et al., 2010). In other modalities than text, consumers are also increasingly encouraged to participate actively rather than consume passively: computer games such as Sony Computer Entertainment's Little Big planet or virtual worlds like Linden Lab's Second-Life are famed for content being mainly created by its users (Humphreys et al., 2005); music artists like Nine Inch Nails or Plastic Ono Band have released their music under open licensing schemes such as Creative Commons, to let users freely modify and "remix" their product (Jarvenpaa and Lang, 2011); innovative pricing strategies such as Radiohead's "Pay what you want for this song" (Page and Garland, 2008) are all examples of letting more participatory control to the user.

However, contrary to tangible manufactured goods, the influence of co-creation on how customers assign value to cultural and intangible goods, and music in particular, remains poorly understood. In particular, the traditional explanation of utilitarian benefits seems unlikely to explain away the value provided by co-creation: one can hardly make music a better fit to anyone's needs. Because music is consumed primarily for enjoyment and emotion regulation (Sloboda et al., 2001), it first seems plausible that the value provided by its co-creation should stem from more positive hedonic responses, e.g. finding co-produced music more beautiful or emotional. Second, because music is an intangible, consuming it is perhaps more accurately described as an "experience", and as such, it may be valued for e.g. its increased immersiveness and ability to "carry the listener away". How such intangible aspects of co-creative consumption interact to produce value has never been formally tested.

In traditional (non co-creative) music consumption, music listeners' intention to purchase a song after listening to it was found to be strongly determined by their "need to re-experience it", the feeling that one would e.g. "like to be able to listen to this song whenever I want to" (North and Oishi, 2006). In turn, the need to re-experience was found to be directly determined by the listeners' evaluation of product quality, i.e. how good/bad, interesting/boring they find the song. Perceived music quality is influenced by both a user's hedonic response (e.g. it is a good song because it made me happy) and experiential response (e.g. it is a bad song, because it didn't "sweep me up") (Lacher and Mizerski, 1994).

If applied to co-creative music consumption, this model provides an interesting opportunity to explore how intangible aspects of co-creation such as experiential response and need to re-experience can contribute to intention to purchase. If it holds, the traditional model would predict that, in order to increase intention to purchase, a cocreative experience needs to increase the perceived quality of the co-produced music. However, it is also possible that the perceived quality of the co-creative experience, as measured e.g. by the user's experiential response, is a driver of purchase intention that's at least as powerful as the perceived quality of the co-created product itself.

To examine these questions, we let two groups of participants rate their experience consuming music in either a traditional or co-creative way, in an experimental situation inspired by the work of American rock band Nine Inch Nails (NIN): in January 2009, the band freely released a large amount of video footage from 3 complete shows of their then-ongoing Lights in the Sky tour. The video material, which amounted to more than $400 \mathrm{~Gb}$ in raw and unedited format, clearly wasn't intended as a final product; on the contrary, the band encouraged their fans to edit it creatively and even produce their own DVD of the show (which they did, see e.g. http://thisoneisonus.org). Re-creating this situation in the laboratory, we asked participants in the cocreative group to produce a video montage using the NIN material, while participants in the non co-creative group were simply tasked to watch a video montage of the same material.

To assess the participants' responses to these two situations, we re-employed the research questionnaire designed by Lacher and Mizerski (1994), testing its validity on the new material. The questionnaire evaluates a variety of possible hedonic responses to music: emotional (e.g. whether positive or negative, aroused or calm), logical/analytical (e.g. the perceived complexity of its constituant themes and repetitions), imaginary (e.g. whether it prompts pictures in our mind) and bodily/sensorial (e.g. whether it makes us want to move or dance). Additionally, the questionnaire measures the listeners' experiential response, perceived product quality, intention to purchase and need to re-rexperience. Using this research question- 
naire, we tested for statistical differences of participants' scores accross the two experimental groups. We hypothesized a significant main effect of consumption condition on the participants' experiential response, with the cocreative music consumption associated with a stronger, more engaging experience. We also hypothesized that this stronger consumer experience should result in perception of better product quality and greater intention to purchase the associated music.

\section{Methodology}

\subsection{Research questionnaire}

The participants' responses to music, in both conditions of either watching or editing a music video, were collected using the questionnaire developped by Lacher and Mizerski (1994) for their study on the evaluation and intention to purchase rock music. It consists of 45 questions, evaluated on 6-point Likert scales anchored by "strongly agree" and "strongly disagree". Questions were designed to measure 13 distinct constructs, each representing a type of response that music evoke in the listener: sensorial response (SEN) (e.g. "I was moving some part of my body in rhythm with the music"); imaginal response (IMA) (e.g. "The song prompted images in my mind"); analytical response (ANA) (e.g. "I wanted to see how the song developed"); and six emotional responses adapted from Asmus (1985): E1 (exuberant), E2 (heroic), E3 (amused), E4 (rage), E5 (sad), E6 (calm). In addition to these hedonic responses to music, the questionnaire also measured constructs that may affect musical purchase: experiential response (EXP) (how absorbing the experience is); evaluation of product quality (QUAL) measured using the index of global product evaluation of Huber and Holbrook (1979); need to re-experience the music (REX)(e.g. "I want to be able to listen to this song whenever I feel like it"); and intention to purchase (PUR) (whether "you would purchase this song the next time you went shopping for music"). See Appendix for the details of the questions loading on each construct.

Judging by the similarity of the type of music considered here with that of Lacher and Mizerski (1994) ("rock", broadly defined), we did not pretest the constructs on the specific music material used here. The questionnaire validity was verified directly on the experimental data of the main experiment (see below).

\subsection{Pilot study: Evaluation of exposure time}

Video editing is notoriously time-consuming. Even professional editors working on a music video will typically spend a great many hours listening to the same song over and over, including repeated loops over given passages of interest. There are well-documented effects of repeated exposure to music: liking for a piece of music typically increase with exposure, with a plateau after about 10 repeats (Bornstein, 1989), followed by a satiation effect (Hargreaves, 1984). It is therefore possible that longer time spent listening to a song while editing its video create an incidental effect of increased liking for the music, or even decreased liking through satiation. In a pilot study, we therefore tested whether the actual time of exposure to music was comparable between the two experimental conditions of the main experiment. Five expert video editors $(\mathrm{M}=23.2, \mathrm{SD}=2.7)$ worked for the same duration (30 minutes) and the same video editing task that the participants of the main study's edit condition, while the audio output of their computer was recorded. We found that only between a half and two-third of the video editing time was spent with active sound $(M=18: 37$, $\mathrm{STD}=5: 02)$ - the rest being mostly mouse clicks and software sounds. We deemed this amount of exposure comparable with the exposure in the watch condition (3 repetitions of a 5-minute music video).

\subsection{Main experiment}

Participants were divided randomly into the 2 experimental conditions: watch and edit.

In the watch condition, participants were asked to watch music video recordings for 2 songs performed live by the band NIN. For each song, participants first listened to one audio-only playback of the song, then watched 3 repetitions of the corresponding music video (each followed by a 2-minute break). After the 3 viewings, participants were asked to fill a survey questionnaire about their impression about the song. After this first sequence, participants were given a 20-minute break, and the same sequence (audio only, 3 video repetitions, questionnaire) was repeated for the second song. The order of presentation of the songs was randomly permutated in the group.

In the edit condition, participants were asked to edit music video recordings from the same 2 songs. For each song, participants were given a pre-arranged project for 
a professional video editing software containing concert footage from 7 different camera angles. Their task was to assemble a continuous single-channel video montage, of the full duration of the song, by selecting, cutting and switching between the 7 angles. The task was simplified by allowing only a limited set of editing operations. The sequence of events in the edit condition was set as follows: first, participants were given a 20-minute hands-on tutorial on the task of video editing, designed and instructed by the third author, a professor of video editing. After the training session, participants listened to one audio-only playback of the first song (in similar fashion to the watch condition), then worked on editing the corresponding music video, individually, for an uninterrupted period of 30 minutes. After the editing period, participants were asked to fill a survey questionnaire about the song (the same as in the watch condition). Participants were then given a 20-minute break, and the same sequence (audio only, 30minute editing period, questionnaire) was repeated for the second song. As in the watch condition, the order of presentation of the songs was randomly permutated in the group.

\subsubsection{Sample}

58 participants (male: 30, female: 28) participated in the experiment, all relatively young $(\mathrm{M}=21.7, \mathrm{STD}=1.1)$ French undergraduate students. Participants in the group declared spending an average 21.4 weekly hours listening to music, with preferences for genres "pop" (quoted $73 \%$ of times), "rock" (72\%) and "hip hop" (52\%). Although $62 \%$ declared taking music lessons in the past, none of the participants identified themselves as musicians, with only $22 \%$ declaring having formal music theory training. 56 participants $(96 \%)$ declared no familiarity with the band NIN - the remaining 2 participants knew the band's name, but did not remember listening to any song in particular in the past. Besides music, participants were also naive with respect to the task of video editing: $87 \%$ declared no previous experience with video editing software and $47 \%$ no experience of video recording.

\subsubsection{Stimulus selection}

Participants in both conditions were presented the same two songs, recordings of live performances by American Rock band Nine Inch Nails during their Lights in The Sky tour, January 2009. In order to test participant responses over a range of personal tastes, songs were selected to include one fast, heavy beat, energetic track with violent mood (Head like a Hole - Trent Reznor (c)1989 TVT Music/Leaving Hope, released TVT 2615-2, see Figure 1a) and one slow, soft track with meditative mood (28 Ghost IV - Trent Reznor and Atticus Ross (C)2008 Trent Reznor/NIN, see Figure 1b). Both songs, subsequently referred as song $\mathrm{H}$ and $\mathrm{G}$, had approximately the same duration (H: 4:57, G: 5:00).

Videos presented in the edit and watch conditions had identical soundtracks, and similar image content: videos presented in the watch condition were edited prior to the experiment by 2 students of the same demographics as our participants, in conditions similar to the edit condition. The videos presented to participants in the watch conditions are available online ${ }^{1}$

\subsubsection{Implementation}

We conducted experiments on 2 consecutive days with both conditions running on each day. Participants in the watch condition were gathered in a calm 20-seat computer-equipped classroom. Participants each sat in front of a computer with a 20-inch LCD display, and watched videos using the OpenSource VLC player controlled remotely for timing. Audio was presented through open-type headphones. Participants in the edit condition were gathered in a calm 15-seat video editing room. Each sat in front of a computer with a 20-inch LCD display. Editing on each computer was done with Apple's Final Cut Pro (v.7) and audio was presented through open-type headphones. In both conditions, participants were seated so they could only minimally influence each other, and were instructed to do the task and respond to the questionnaire without sharing information between one another.

\subsubsection{Validation of research questionnaire}

A confirmatory factor analysis was performed to establish whether the measures loaded on their respective constructs in a similar manner to Lacher and Mizerski (1994). A three-factor model was tested for the two sensorial scale items, the three imaginal scale items and the three needto-reexperience items, which all loaded correctly. A sixfactor model was tested for the eighteen emotional scale

${ }^{1}$ http://youtu.be/ytA70OYfqRQ and http://youtu.be/De1F4_8wVtE 
Figure 1: Snapshots from the video material presented in both conditions for songs "Head like a Hole" (1a) and "28 Ghost IV" (1b)

(a) Snapshots from song "Head like a Hole", a fast, heavy beat, energetic track with violent mood

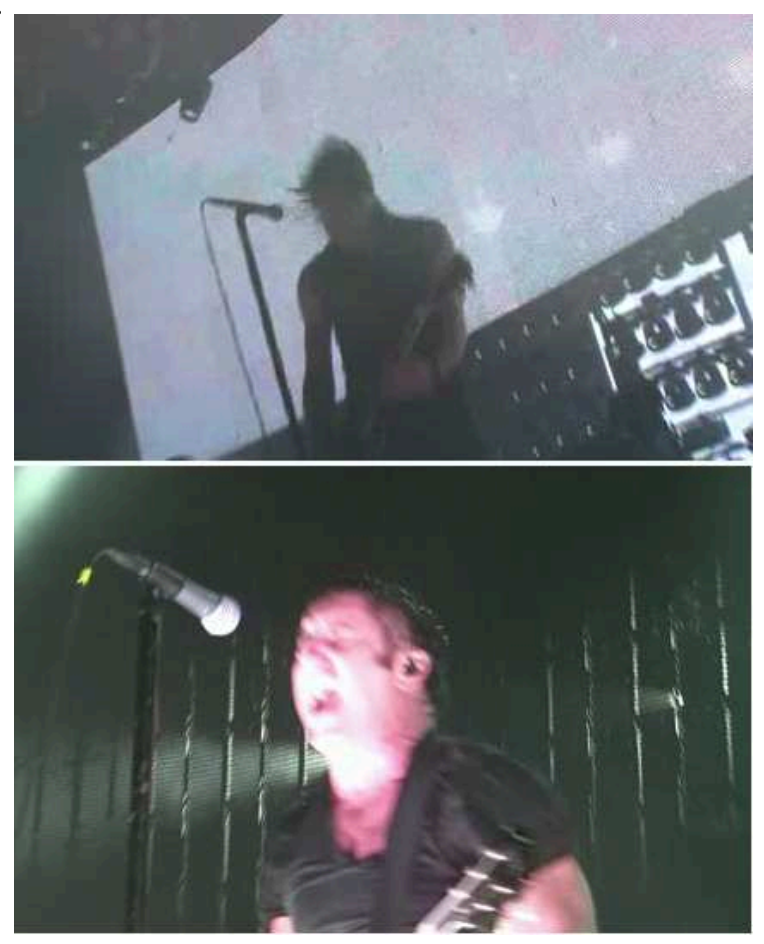

items, seveteen of which loaded correctly. We then computed Cronbach's alpha reliability coefficients for each construct, which ranged from from 0.58 to 0.95 . All constructs but two met the internal consistency threshold of 0.70. (\{see details in Appendix). The measures were therefore used in the main experiment.

\subsubsection{Main results}

We analysed results as a repeated-measure MANOVA with song ( 2 levels) as a repeated factor, and condition (2 levels) as a between-subject factor.

Song had a strongly significant main effect on the tested measures: Multivariate $\mathrm{F}(13,44)=53.4, \mathrm{p}<.0001$, with significant posthoc differences (Fisher LSD) on all but one (E2) of the measured constructs (see Table 1a). As expected, the hedonic responses of both songs were widely different. Participants found song $\mathrm{H}$ to be more exhuber- (b) Snapshots from song "28 Ghost IV", a slow, soft track with a meditative mood.
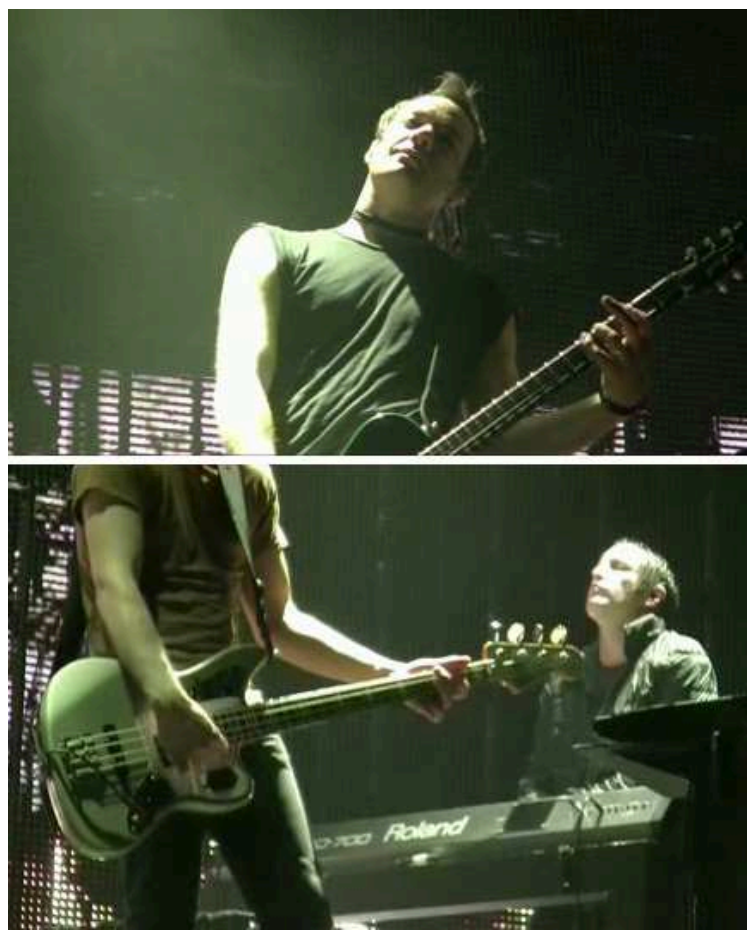

ant (E1), more hateful (E4) and more amusing (E3), and had stronger sensorial response - all in accordance with the song's powerful, heavy-metal instrumentation, strong percussion, medium tempo and high overall energy. On the contrary, Song G imparted more imaginal, analytical and experiential response, consistently with the song's reflective atmosphere, slow tempo, modal harmony and lack of strong percussive structure. Participants judged song G of better quality, and has greater intention to purchase and re-experience it.

Condition had a marginally significant effect: Multivariate $\mathrm{F}(13,44)=1.646, \mathrm{p}=0.11$, with significant posthoc differences (Fisher LSD) on 5 of the 13 constructs at the $p<.05$ level: E1, E6, QUAL, REX, PUR, and 8 of the 13 constructs at the marginal $p<0.10$ level: ANA, E2, EXP. Participants who edited song $\mathrm{H}$ perceived it as being less exuberant (E1) than those who simply watched it, 
had less analytical response, a more negative evaluation of product quality, and decreased need to experience it (Table 1b). Participants who edited, instead of watched, song $\mathrm{G}$ judged it as less exhuberant, less heroic, amused and calm, judged the song of lower quality, had a lower imaginal response, experiential response, need to re-experience and intention to purchase it (Table 1c). There was no interaction between song and condition $(\mathrm{F}(13,44)=.56$, $p=0.86)$.

On the whole, the editing condition therefore had a negative impact on the participants' responses for both songs. Both songs were judged less exuberant and amusing when edited than watched. Both songs yielded lower experiential response and lower evaluation of product quality in the edit condition, i.e. participants "experienced" them more strongly and "liked" them better when watched. Finally, participants who edited the songs expressed a lower need to re-experience the music and a lower intention to purchase it after they spent time editing rather than watching.

Multivariate regression analysis in the watch condition (Figure 2a) showed that four of the hedonic responses (E2-heroic, E6-calm, Sensorial, Analytical) had significant positive relationships to the experiential response. Emotional constructs (with the exception of E2 and E6) appeared to have only limited influence on the experiential response and product quality. In the watch condition, evaluation of product quality was mainly influenced by the experiential response. The evaluation of product quality, in turn, was the only significant influence on the need to re-experience the music. Finally, the need to reexperience the music was the strongest direct influence $(\beta=.62)$ on the listener's intention to purchase the new music.

Multivariate regression analysis in the edit condition (2b) showed a sparser, and remarkably different network of correlations than in the watch condition. The emotional responses E1 (exhuberant), E6 (calm) and the imaginal responses were the sole significant influences of the experiential response (both positive), while sensorial and analytical responses did not appear to contribute. Furthermore, the imaginary response, which had a negative influence $(\beta=-0.30)$ on product quality in the watch condition, had a positive influence in edit $(\beta=.24)$ : songs which prompted mental images were judged less pleasing when watching a video, but more pleasing when trying to edit it. Finally, the experiential response in the edit condition was found the only significant influence on the intention to purchase $(\beta=.32)$; surprisingly, the need to re-experience the music did not appear to influence the act of purchase, whereas it was the unique positive influence in the watch condition. More surprisingly perhaps, this implies that product quality had no direct or mediated influence on the decision of purchase.

\section{Discussion}

The purpose of this study was to test the influence of intangible aspects of co-creation, such as experiential response and need to re-experience, on consumers' intention to purchase music. Our hypothesis was that consumers in the co-creative condition would have a stronger experiential response and, consequently, a more positive evaluation of product quality and greater willingness to purchase the music.

On the one hand, our results directly contradicted our expectation that the co-creative condition would generate greater experiential response. Users who edited rather than watched both songs had a lower experiential response, lower evaluation of product quality, lower need to re-experience the music, and a lower intention to purchase it. On the other hand, even if the participants' experiential response decreased in the co-creative condition, regression analyses confirmed that it did gain importance in predicting the editing participant's intention to purchase. More precisely, contrary to the watch condition, the experiential response was a significant and direct influence of intention to purchase in the edit condition; moreover, neither product quality or need to re-experience responses were significant regressors of intention to purchase.

This study is by no means the first to find a negative outcome of co-creation on purchase intention, and several factors may explain it in our context. First, participants were selected to be neutral with respect to the task, in order to control for their intrinsic motivation (Füller et al., 2012): they had no prior experience of video editing, and all underwent the same training prior to the experiment. However, Fuchs et al. (2010) show that co-production may not be strong when consumers do not believe that they have the relevant competence to make sound decisions. Sometimes, co-produced products are perceived to be lower in quality, and fail to signal high status in luxury goods (Fuchs et al., 2013). It is therefore possible that our 
Table 1: Average ratings in each construct, comparing songs (1a) and conditions in each song (1b, 1c). Legend: SEN sensorial response, IMA: imaginary response, REX: need to re-experience, E1: exhuberant, E2:heroic, E3: amusing, E4: rage, E5: sad, E6: calm, ANA: analytical response, EXP: experiential response, QUAL: evaluation of product quality, REX: need to re-experience, PUR: intention to purchase.

(a) Main effect of song: averaged ratings in each construct, compared from song $\mathrm{H}$ to song G. Constructs marked with ** significant at the $\mathrm{p}=.001$ level (Fisher LSD post-hoc)

\begin{tabular}{ccc}
\hline \hline Construct & Song H & Song G \\
\hline SEN** & $M=3.62$ & $M=2.37$ \\
IMA** $^{*}$ & $M=2.62$ & $M=3.85$ \\
ANA** & $M=3.22$ & $M=3.99$ \\
E1** & $M=4.11$ & $M=2.72$ \\
E2 (n.s.) & $M=3.02$ & $M=2.95$ \\
E3** & $M=2.22$ & $M=1.58$ \\
E4** & $M=3.97$ & $M=1.79$ \\
E5** & $M=1.99$ & $M=3.80$ \\
E6** & $M=1.84$ & $M=4.54$ \\
EXP** & $M=2.54$ & $M=3.71$ \\
QUAL** & $M=2.44$ & $M=3.54$ \\
REX** & $M=2.59$ & $M=3.82$ \\
PUR** & $M=3.49$ & $M=4.08$ \\
\hline
\end{tabular}

(b) Main effect of condition: song H. Constructs marked with *: $p<0.05$ level; (*) $p<0.1$ (Fisher LSD post-hoc). Legend: same as 1a.

\begin{tabular}{ccc}
\hline \hline Construct & Watch & Edit \\
\hline SEN & $\mathrm{M}=3.65$ & $\mathrm{M}=3.62$ \\
IMA & $\mathrm{M}=2.74$ & $\mathrm{M}=2.56$ \\
ANA $\left.{ }^{*}\right)$ & $\mathrm{M}=3.48$ & $\mathrm{M}=3.00$ \\
E1* & $\mathrm{M}=4.32$ & $\mathrm{M}=3.91$ \\
E2 & $\mathrm{M}=2.95$ & $\mathrm{M}=2.58$ \\
E3 & $\mathrm{M}=2.22$ & $\mathrm{M}=2.22$ \\
E4 & $\mathrm{M}=4.01$ & $\mathrm{M}=3.93$ \\
E5 & $\mathrm{M}=2.09$ & $\mathrm{M}=1.90$ \\
E6 & $\mathrm{M}=1.90$ & $\mathrm{M}=1.78$ \\
EXP & $\mathrm{M}=2.72$ & $\mathrm{M}=2.41$ \\
QUAL $(*)$ & $\mathrm{M}=3.72$ & $\mathrm{M}=3.31$ \\
REX(*) & $\mathrm{M}=2.93$ & $\mathrm{M}=2.31$ \\
PUR & $\mathrm{M}=2.66$ & $\mathrm{M}=2.26$ \\
\hline
\end{tabular}

(c) Main effect of condition: song G. Constructs marked with *: $p<0.05$ level; (*) $p<0.1$ (Fisher LSD post-hoc). Legend: same as $1 \mathrm{a}$.

\begin{tabular}{ccc}
\hline \hline Construct & Watch & Edit \\
\hline SEN & $\mathrm{M}=2.36$ & $\mathrm{M}=2.37$ \\
IMA(*) & $\mathrm{M}=4.16$ & $\mathrm{M}=3.54$ \\
ANA & $\mathrm{M}=4.13$ & $\mathrm{M}=3.84$ \\
E1* & $\mathrm{M}=2.98$ & $\mathrm{M}=2.45$ \\
E2(*) & $\mathrm{M}=2.89$ & $\mathrm{M}=2.39$ \\
E3(*) & $\mathrm{M}=1.79$ & $\mathrm{M}=1.37$ \\
E4 & $\mathrm{M}=1.71$ & $\mathrm{M}=1.88$ \\
E5 & $\mathrm{M}=3.80$ & $\mathrm{M}=3.80$ \\
E6* & $\mathrm{M}=5.19$ & $\mathrm{M}=4.68$ \\
EXP(*) & $\mathrm{M}=4.00$ & $\mathrm{M}=3.42$ \\
QUAL* & $\mathrm{M}=4.29$ & $\mathrm{M}=3.78$ \\
REX* $^{*}$ & $\mathrm{M}=4.16$ & $\mathrm{M}=3.48$ \\
PUR(*) & $\mathrm{M}=3.81$ & $\mathrm{M}=3.26$ \\
\hline
\end{tabular}

participants were, or deemed themselves, not competent enough for the task. Even if their video montages were by no means complete failures, participants may have experienced that they weren't able to properly express their preferences (Franke and Steger, 2009), or had a low feeling of accomplishment (Franke and Kaiser, 2010): they could have done so much better if only they'd knew a little more.

Second, participants were also selected to be neutral with respect with the band, with no prior knowledge or liking for the music of NIN. Chan and Lam (4864) showed that the effects of customer participation in value creation depend on participant' cultural value orientations, and may backfire; in addition, coproduction was shown to lead to more positive outcome when customers have greater product involvement (Franke and Steger, 2009). It is therefore possible that engaging in cocreation on material for which one has no prior interest is simply not going to work. Had participants known more about the band and its music, they may also have had better insights into their own preferences, another pre- dicter of positive outcome (Franke and Steger, 2009).In the present experiment, these two variables (task competence, prior attitude to the band) were controlled, but not measured. A follow up study should therefore either consider other participant groups, such as professional video editors and/or NIN fans, or better, introduce these variables as moderators in the analysis.

While the co-creative situation simulated here did not result in a more positive experience or more intention to purchase, we found that it was the participant's experiential response (i.e. how much users enjoyed, or disliked, the process) and not the evalution of product quality (i.e. how good/bad they found the product) which drove the effect. This finding is in support of the literature's recent emphasis on experiential and "process" benefits of co-creative consumption in the case of tangible goods (Schreier, 2006; Fuchs et al., 2010; Franke and Kaiser, 2010); further, it suggests that utilitarian/product quality benefits are not the most important variable for the coproduction of cultural and intangible goods.

In this work, we measured the participants' experien- 
Figure 2: Multivariate regression analysis of the EXP, QUAL, REX and PUR scales on each of the hedonic response scales (SEN, IMA, ANA and E1-E6), in the form of a path diagrams, separated for condition watch (2a) and edit (2b). Standardized regression coefficients, $t$ scores and $p$ values for all paths were estimated with least-squares multivariate regression. Only significative regressions displayed (solid line: $\mathrm{p}<0.01$; doted line: $\mathrm{p}<0.05)$. See Tables $2 \mathrm{a}$ and $2 \mathrm{~b}$ for correlation matrices.

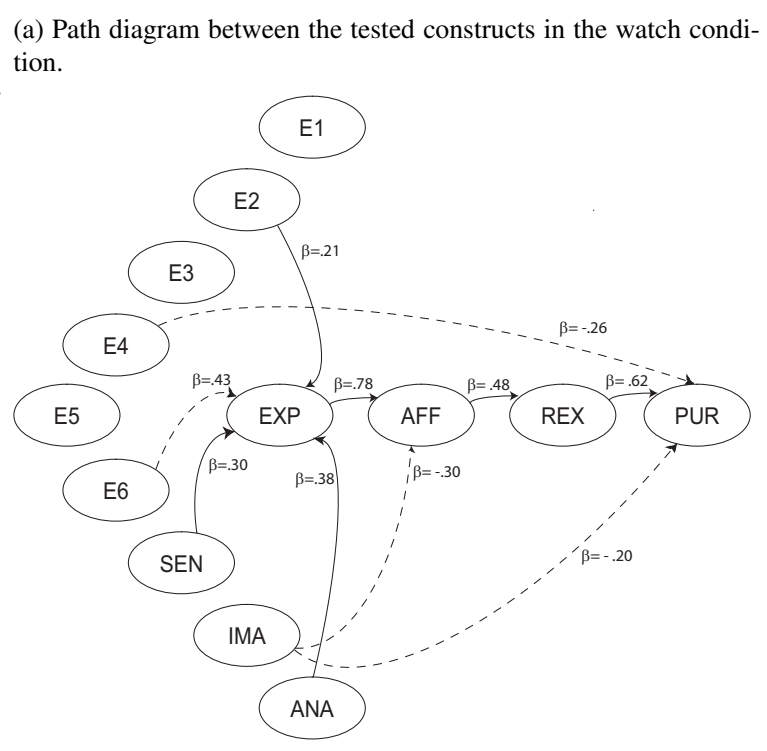

tial response by asking questions about e.g. how "carried off" they were by the music, how "deeply" they felt about the songs, and how long they think they would continue to "feel" the experience of the songs after they finish. While refering explicitely to the songs, these judgements cannot be separated from the conditions of reception of the music, i.e. watching or editing it. On the one hand, because video editing is a repetitive and non-linear task, the normal time flow of a song is broken, passages are listened repeteadly, or skipped. Such non-linear listening is likely to e.g. prevent a song's build-up and influence how "deeply" felt the music is. On the other hand, the ability to navigate through multiple views of the music and to participate in the music's construction may create a more active and long-lasting involvement with the material. It is therefore difficult to conclude whether it is the experiential response to the music (the experience of consumption), or to the task (the consumption of experience), which is most influential on the listener's subsequent intention to purchase.

From a methodological perspective, it will therefore be necessary in future work to construct measures of experi- (b) Path diagram between the tested constructs in the edit condition.

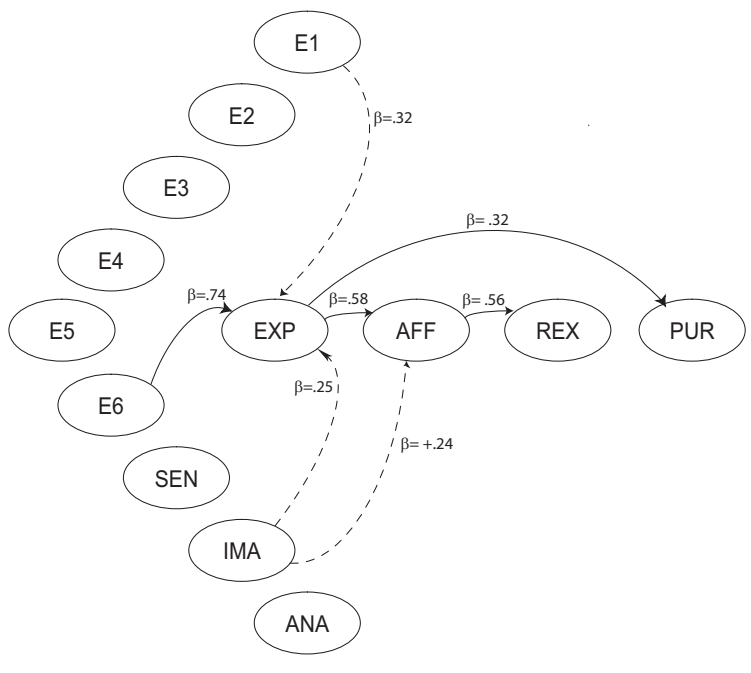

ence quality that specifically target the task. Besides hedonic responses to the music itself, there are a variety of non-music-related factors that can predict the perceived quality of the co-creative experience, e.g. task enjoyment, perceived competence and autonomy (Dahl and Moreau, 2007), perceived accomplishement (Franke and Kaiser, 2010), all of which have potential to be drivers in the final decision to purchase. Constructs from the psychology of motivation, such as flow (an optimal compromise of challenge and skills) (Csikszentmihalyi and Csikzentmihaly, 1991), as well as the scales used to measure optimal experience in e.g. sport performance (Jackson et al., 1996), could in particular be useful complements to the measures used in the present work.

Finally, beyond what we measured here as experiential response, it was surprising to find that another intangible aspect of experience, the need to re-experience, did not show an effect on intention to purchase. This may indicate a change in consumers' attitude towards music purchase since the pre-internet times of Lacher and Mizerski (1994). Need to re-experience can be seen as the consequence of an economic model in which one has to 
buy music in order to control the ability to consume it. However, this model has changed dramatically. With the emergence of file-sharing and subscription-based streaming services, purchasing music is no longer the only way to control where and when a given piece of music can be experienced. Consumers now need, literally, new reasons to buy. In the context of coproduced intangible goods, purchase may in effect have become less of a need (to own the outcome and control the conditions of its consumption) and more of an acknowledgement (of the quality of a prior and possibly free experience).

There are several limitations to our study. First, we used an hypothesis-testing design, which aimed at investigating score differences along various constructs between two consumption situations, rather than a model-testing design, aiming to validate a path diagram postulated a priori. While regression analyses in the edit condition suggested important adjustments made to the model of Lacher and Mizerski (1994), with increased influence of the experiential response and decreased influence of product quality and need to re-experience, these observations do not constitute model testing, and more work is needed to establish such a model. Second, it is unclear how much of the patterns observed in our study are due to the general situation of co-creative consumption, or to cognitive and technical specificities of the video editing task used here. For instance, regression analyses in both conditions indicated an effect of the imaginal response on the participants' evalution of product quality that didn't exist in the audio-only situation of Lacher and Mizerski (1994). It is therefore possible that this is a specificity of using video material and that it would not be the case, e.g., if participants were instead tasked to, e.g., design an album cover or do audio-only editing. Further work will be also needed to clarify these factors.

\section{Acknowledgements}

Work funded by European Research Council (ERC) projet CREAM 335536 (to JJA).

\section{Appendix: Research questionnaire}

As described in Section 2.1, this study re-employed the scales developped by Lacher and Mizerski (1994), mea- suring 13 distinct constructs, each representing a type of response that music evoke in the listener.

Sensorial Response (2 questions, six-point scale, from "strongly disagree" to "strongly agree'):

1. I was moving some part of my body (head, foot, hand) in rhythm with the music

2. I wanted to dance to the music

Imaginal Response (3 questions, six-point scale, from "strongly disagree" to "strongly agree'):

1. The song created a picture in my mind

2. The song made me remember something

3. The song prompted images in my mind

Analytical response (2 questions, six-point scale, from "strongly disagree" to "strongly agree'):

1. I wanted to see how the song developed

2. I analyzed the way the song was put together and why it came out the way it did

Emotional response (18 adjectives, six-point scale, from "strongly disagree" to "strongly agree'):

1. Vigorous (factor: E1 “exuberant”)

2. Vibrant (E1)

3. Exuberant (E1)

4. Heroic (factor: E2 "patriotic")

5. Victorious (E2)

6. Patriotic (E2)

7. Amused (factor: E3 "amused")

8. Humorous (E3)

9. Comical (E3)

10. Hate (factor: E4 "rage")

11. Anger (E4)

12. Rage (E4)

13. Sad (factor: E5 "sad")

14. Blue (E5)

15. Depressed (E5)

16. Calm (factor: E6 “calm")

17. Tranquil (E5)

18. Relaxing (E5)

Experiential response (5 questions, six-point scale, from "strongly disagree" to "strongly agree'):

1. I felt "carried off" by the music 
2. I felt as if I were part of the song

3. I felt deeply about the song

4. I will feel the experience of this song for a while

5. I "got into" the song

Evaluation of product quality (9 bipolar adjectives, separated by a six-point scale):

1. good...bad

2. interesting...boring

3. tasty...distasteful

4. exciting...dull

5. pleasant...unpleasant

6. memorable...forgettable

7. talented...untalented

8. tasteful...tasteless

9. creative...unimaginative

Need to re-experience (3 questions, six-point scale, from "strongly disagree" to "strongly agree'):

1. I would enjoy listening to this song again

2. I would like to play this song for my friends

3. I want to be able to listen to this song whenever I feel like it

Intention to purchase ( 3 bipolar adjectives, separated by a six-point scale):

"Please circle the number that best describes whether you would purchase this song the next time you went shopping for music:"

1. likely...unlikely

2. possible...impossible

3. probable...improbable

\section{Validation of research questionnaire}

A confirmatory factor analysis (with varimax rotation) was performed to establish whether the measures loaded on their respective constructs in a similar manner as the original study Lacher and Mizerski (1994). A threefactor model was tested for the two sensorial scale items, the three imaginal scale items and the three need-toreexperience items, which all loaded correctly (all factors $>0.78, \mathrm{VAE}=81 \%$ ). A six-factor model was tested for the eighteen emotional scale items: all but one item loaded correctly (all but one factors $>0.45$, VAE $=69 \%$ ). For the exhuberant scale, item 'vibrant" loaded preferably on E2(heroic) (load: 0.53) rather than on E1(exhuberant) (load: 0.41), and for the sad scale, item "blue" had a loading of only 0.21 , compared to items "sad" (0.77) and "depressed" $(0.45)$.

We then computed reliability coefficients for each construct (Carmines and Zeller, 1979). Cronbach's alpha for the experiential response $(0.91)$, product quality $(0.92)$, need-to-reexperience $(0.92)$ and intention to purchase (0.94) indicated excellent consistency. The sensorial response (alpha:0.76) and imaginal response (alpha: 0.84) both met the basic research guideline alpha requirement of .70 (Nunnally, 1978). For the emotional response, all but one construct met the .70 requirement: E2 (alpha:0.75), E3 (0.78), E4 (0.87), E5 (0.72) and E6 (0.95). Emotional construct E1 has an alpha of 0.58, and the analytical response had an alpha of 0.66 , but similar scores were judged acceptable in Lacher and Mizerski (1994).

\section{References}

\section{References}

Asmus, E. P., 1985. The development of a multidimensional instrument for the measurement of affective responses to music. Psychology of Music 13 (1), 19-30.

Bornstein, R. F., 1989. Exposure and affect: Overview and meta-analysis of research. Psychological Bulletin 106, 265-289.

Chan, Y., Lam, 48-64. Is customer participation in value creation a double-edged sword? evidence from professional financial services across cultures. Journal of Marketing 74.

Csikszentmihalyi, M., Csikzentmihaly, M., 1991. Flow: The psychology of optimal experience. Vol. 41. HarperPerennial New York.

Dahl, Moreau, 2007. Thinking inside the box: why consumers enjoy constrained creative experiences. Journal of Marketing Research 44, 357-389.

Durgee, J., 2003. The co-creation of meaning between marketer and consumers. step 1: how marketing creatives interpret consumer motivations. 
Franke, Piller, 2004. Toolkits for user innovation and design: an exploration of user interaction and value creation. Journal of Product Innovation Management 21.

Franke, K., Steger, 2009. Testing the value of customization: when do customers really prefer products tailored to their preferences? Journal of Marketing 73, 103121.

Franke, Schreier, M., Kaiser, 2010. The "i designed it myself effect" in mass customization. Management Science $56(1)$.

Fuchs, Prandelli, Schreier, M., 2010. The psychological effects of empowerment strategies on consumer product demand. Journal of Marketing 74(1).

Fuchs, Prandelli, Schreier, M., Dahl, 2013. All that is users might not be gold: How labling products as user designed backfires in the context of luxury fashion brand. Journal of Marketing 77, 75-91.

Füller, J., 2010. Refining virtual co-creation from a consumer perspective. California Management Review 52 (2), 98-122.

Füller, J., Matzler, K., Hutter, K., Hautz, J., 2012. Consumers' creative talent: Which characteristics qualify consumers for open innovation projects? an exploration of asymmetrical effects. Creativity and Innovation Management 21, 247-262.

Hargreaves, D. J., 1984. The effects of repetition on liking for music. Journal of Research in Music Education 32.

Huber, J., Holbrook, M. B., 1979. Using attribute ratings for product positioning: Some distinctions among compositional approaches. Journal of Marketing Research 16, 507-516.

Humphreys, S., Fitzgerald, B., Banks, J., Suzor, N., 2005. Fan-based production for computer games: User-led innovation, the 'drift of value' and intellectual property rights. Media International Australia, Incorporating Culture \& Policy, Issue 114.

Jackson, S. A., Marsh, H. W., et al., 1996. Development and validation of a scale to measure optimal experience: The flow state scale. Journal of sport and exercise psychology 18, 17-35.
Jarvenpaa, S. L., Lang, K. R., 2011. Boundary management in online communities: case studies of the nine inch nails and ccmixter music remix sites. Long Range Planning 44 (5), 440-457.

Lacher, K., Mizerski, R., 1994. An exploratory study of the responses and relationships involved in the evaluation of, and in the intention to purchase new rock music. The Journal of Consumer Research 21 (2), 366-380.

North, A. C., Oishi, A., 2006. Music cd purchase decisions. Journal of Applied Social Psychology 36 (12), 3043-3084.

Page, W., Garland, E., 2008. In rainbows, on torrents. Economic Insight 10.

Prahalad, Ramaswany, 2004. The future of competition: co-creating unique value with customers. Boston, MA: Harvard Business School.

Purcell, K., Rainie, L., Mitchell, A., Rosenthal, T., Olmstead, K., 2010. Understanding the participatory news consumer. Pew Internet \& American Life Project, http://www.pewinternet.org/Reports/2010/OnlineNews.aspx, accessed on Sept. 1, 2010.

Schreier, M., 2006. The value increment of masscustomized products: an empirical assessment. Journal of Consumer Behaviour 5(4), 317-327.

Sloboda, J. A., O’Neill, S. A., Ivaldi, A., 2001. Functions of music in everyday life: An exploratory study using the experience sampling method. Musicae scientiae 5 (1), 9-32. 

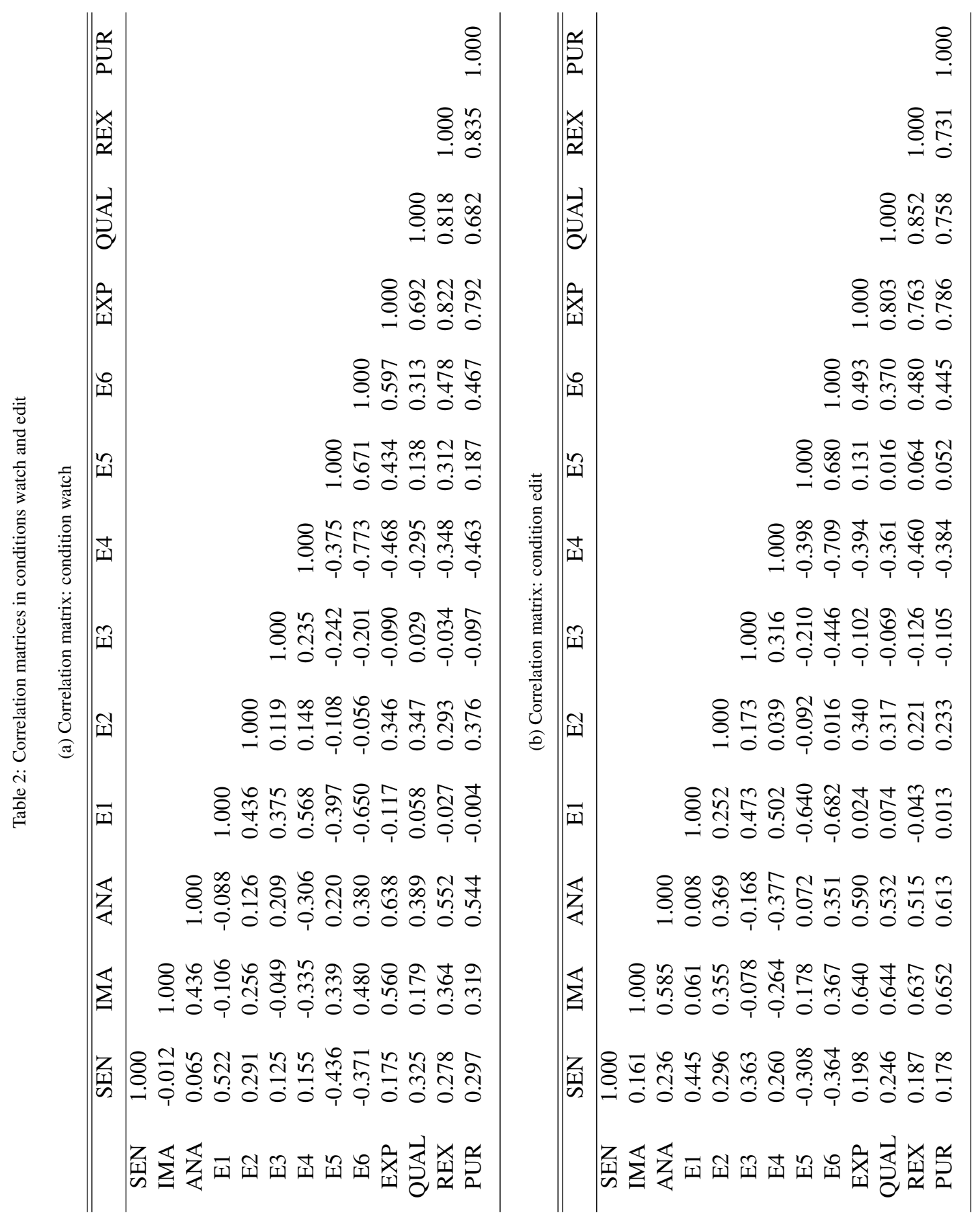